\title{
Modeling and Research of Bus Equipped with Dynamic Stability Control System
}

\author{
V. DZERKELIS*, V. LUKOŠEVIČIUS**, E. GIRKONTAS***, R. KERŠYS****, \\ H. SAR *****, R. MAKARAS******, R. SKVIRECKAS******* \\ *Kaunas University of Technology, Kaunas, Lithuania, E-mail: vytautas.dzerkelis@ktu.lt \\ **Kaunas University of Technology, Kaunas, Lithuania, E-mail: vaidas.lukosevicius@ktu.lt \\ ***Kaunas University of Technology, Kaunas, Lithuania \\ ****Kaunas University of Technology, Kaunas, Lithuania, E-mail: robertas.kersys@ktu.lt \\ *****Institute of Vehicles, Warsaw University of Technology, Warsaw, Poland \\ ******Kaunas University of Technology, Kaunas, Lithuania, E-mail: rolandas.makaras@ktu.lt \\ *******Kaunas University of Technology, Kaunas, Lithuania, E-mail: ramunas.skvireckas@ktu.lt \\ cross $^{\text {ref }}$ http://dx.doi.org/10.5755/j01.mech.24.1.18246
}

\section{Introduction}

Passenger transportation by city and intercity buses has increased significantly in the recent years. Bus trip is considered to be one of the safest means of land road transportation. The number of casualties caused by buses in 2006 accounted for $2.5 \%$ of all road traffic accidents. The results suggest that the increasing demand for bus trips in future will inevitably involve higher number of accidents. This calls for maximum possible increase of passenger safety by different methods [1,2].

Drivers often are incapable of handling the task of vehicle stabilization in critical situations. For these reasons, electronic stability control systems have started to be installed in passenger cars and sports utility vehicles (SUVs) [3]. Studies have demonstrated that an ESP installed in a vehicle could reduce the chance of a traffic accident by $45 \%$, where the accident is caused by unsafe driving trajectory [4].

Two types of heavy vehicle accidents associated with vehicle instability could be identified: vehicle rollover and vehicle drift from the desired trajectory. Accidents involving vehicle drift from the desired trajectory are caused by one or several vehicle axles drifting from the required cornering trajectory. Where the force parallel to road surface acting on the vehicle is greater than the wheel

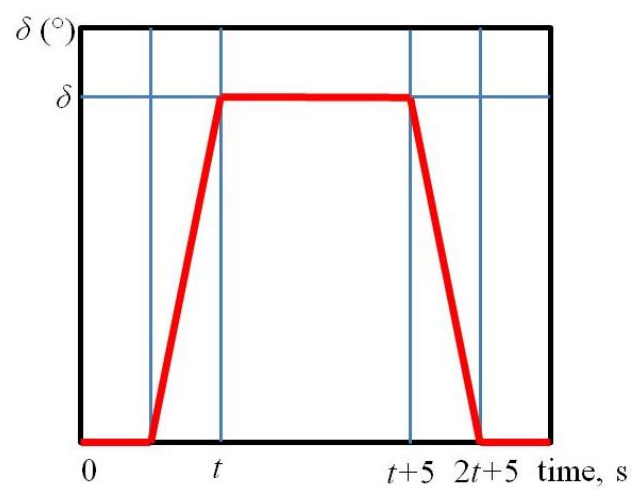

Fig. 1 Steering wheel angle variation at ramp manoeuvre [7] to road grip force, the vehicle naturally starts slipping [5].

Key factors causing loss of longitudinal stability or rollover of commercial vehicles are the following: driver's errors, accidents associated with poor infrastructure, or poor road surface [6].

This paper is aimed at analysing manoeuvre stability of an intercity bus equipped with dynamic stability control system and reliability of this system using the MSC.Adams software. Relevance of the system in buses of this type will also be assessed in the paper.

\section{Review of the methodology of the tests}

Test methodology for heavy-duty vehicles, such as buses, is not a universal solution; however, tests similar to those applied to light-duty vehicles are usually used. National Highway Traffic Safety Administration (NHTSA) uses the following tests for testing heavy-duty vehicle stability:

- constant radius test, involving constantly increasing velocity of vehicle;

- slowly increasing steer test;

- ramp steering maneuver;

- ramp with dwell;

- sine with dwell;

- half-sine with dwell.

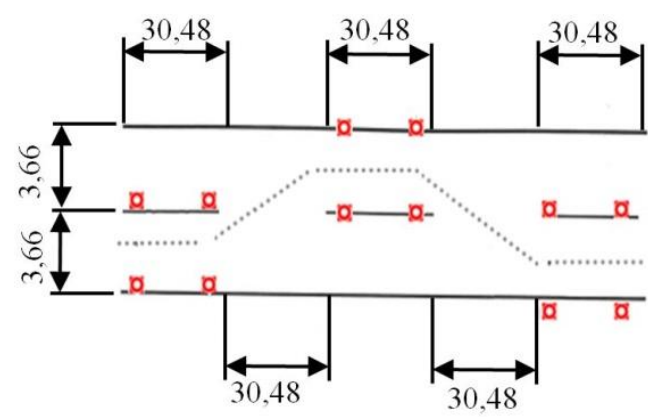

Fig. 2 Trajectory and dimensions (m) of double-lane change manoeuvre by the Altoona Bus Research and Testing Center [8] 
Ramp test is based on constant steering until the required steering wheel angle is reached. In case of a test sequence, conditions become more complex as the initial velocity is increased. In its tests, NHTSA increases the velocity at $3.2 \mathrm{~km} / \mathrm{h}(2 \mathrm{mph})$ increments starting with the initial velocity of $32 \mathrm{~km} / \mathrm{h}(20 \mathrm{mph})$. Acceleration increment is reduced to $1.6 \mathrm{~km} / \mathrm{h}(1 \mathrm{mph})$, when the tested vehicle loses stability. Fig. 1 demonstrates variation of steering wheel angle profile during the test. The test is completed as soon as one of the following conditions is met [7]:

- vehicle remains stable after reaching the velocity of $50 \mathrm{mph}(80 \mathrm{~km} / \mathrm{h})$;

- driving axle wheel lifts 2 inches $(\sim 5 \mathrm{~cm})$ off the ground;

- driven axle wheel lifts 2 inches $(\sim 5 \mathrm{~cm})$ off the ground.

Double-lane change manoeuvre. The test involves a bus performing the double-lane change manoeuvre

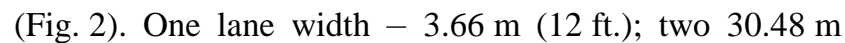
$(100 \mathrm{ft})$ gate spacings are provided for the bus to perform the lane change. This manoeuvre is usually performed several times, with the bus changing lanes, first, left to right, and then right to left. The test is considered to be successful, if the tested bus completes the track at the predefined constant velocity without hitting the road cones off. Maximum test velocity of the bus is usually $72 \mathrm{~km} / \mathrm{h}$ (45 mph) [8].

\section{Model design}

Investigation of vehicle motion through numerical calculations is widely applied. The reason for this is that it is regarded as quite easy and cheap method of active safety systems validation. The question is: which mathematical model should be chosen? Different models can be applied from very simple two-degree-of-freedom (2-DOF) "bicycle" model $[9,10]$ to much more sophisticated models with many DOFs, including different interactions [11, 12]. In case of analyzing lateral dynamics of a vehicle it is necessary to describe the side slip phenomenon of tyres as presented by $[13,14]$. However, too much complicated models do not always mean better solution, because of the problem of identifying parameters of model. Apart from data sheets of a vehicle (wheelbase, wheel track, masses of a vehicle etc.), many parameters require test rig measurements, which can guarantee the low level of error, contrary to estimation, which is sometimes performed on the basis of empirical equations.

This paper is largely focused on an ABS-based distributed braking system. This is currently the most widespread system in automotive industry [15]. This vehicle model is comprised of seven degrees of freedom. Lateral and longitudinal velocity (usually indicated as $\dot{x}$ and $\dot{y}$ ) and yaw rate $(\dot{\psi})$ create three degrees of freedom related to the vehicle body. Angular velocity of wheels ( $w_{p k}, w_{p d}$, $\left.w_{g k}, w_{g d}\right)$ create another four degrees of freedom.

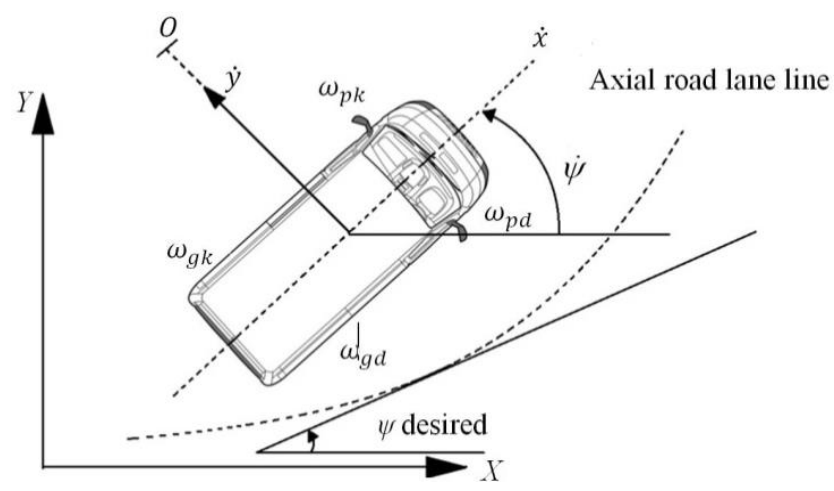

Fig. 3 Bus parameters become relevant during its cornering

Assume that steering wheel angle is indicated as $\delta$. Longitudinal reactions of all wheels are $F_{x p k}, F_{x p d}, F_{x g k}$, $F_{x g d}$. Lateral reactions of wheels are indicated as, respectively, $F_{y p k}, F_{y p d}, F_{y g k}, F_{y g d}$.

The desired values of yaw rate and slip angle are not always possible to obtain. Attempts to achieve higher value of yaw rate than desired would be unsafe, if the grip ratio is not capable of supporting such velocity. This means that the desired value of yaw rate should be limited by the tyre to road grip function.

Linear dependence between deviation from the desired driving trajectory and steering wheel angle forms, where vehicle is controlled by modes involving small slip angles and no corrections by the steering wheel:

yaw rate $(\psi)=($ steering wheel angle $)$ multiplied by (increase of yaw rate).

Yaw rate is also associated with lateral accelera-

$$
\psi=(\text { transverse acceleration }) /(\text { vehicle velocity). }
$$

Any of the above dependences could be applied to identification of an ideal vehicle yaw rate under the defined conditions. Difference between actual and ideal yaw rates is employed in control of transverse stability:

$$
\begin{aligned}
& (\text { vehicle slip value })=(\text { actual yaw rate })- \\
& -(\text { ideal yaw rate }) .
\end{aligned}
$$

The vehicle is considered to be too susceptible to skidding, where it demonstrates positive slip value. Where the slip value is negative, the vehicle is considered to be not manoeuvrable enough. Besides these to types, there is the third type - neutral manoeuvrability.

Stability factor $K$ is used to assess vehicle behaviour while cornering:

$$
K=m \frac{c_{\alpha g} l_{g}-c_{\alpha p}^{\prime} l_{p}}{c_{\alpha p}^{\prime} c_{\alpha g} l},
$$


where $m$ is vehicle weight; $l$ is wheelbase; $l_{g}$ and $l_{p}$ are distance from centre of mass to axle; $c_{\alpha p}$ is front axle stiffness (based on tyre stiffness and pneumatic model); $c_{\text {ag }}$ is rear axle stiffness [16].

Parameters of the studied numerical model have been determined in the MSC.Adams software application. In order to design a mechatronic system in Adams/Car application, both the ABS and ESP control systems must be designed as well (Fig. 4). Add-in Adams/Mechatronics to the MSC.Adams software is used for simulation of operations of these systems [17]. The studied model is designed using Adams/Truck general suspension templates. Simulation begins with design of an assembly unit of the required wheelbase; the centre of mass is determined by the weight values of main components and their layout according to the reference point.

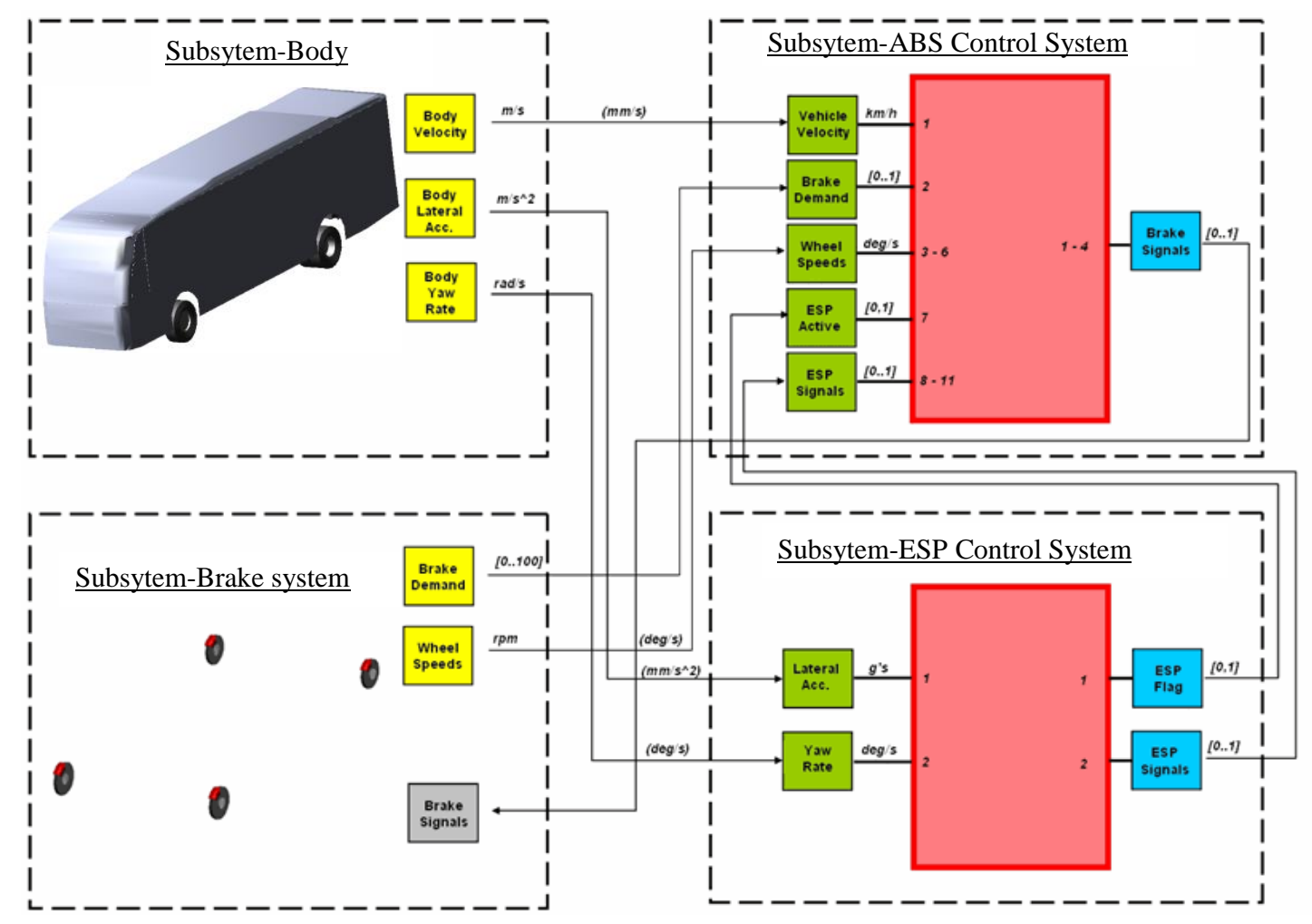

Fig. 4 Signals of stability control system and their connections [17]

Two identical bus models with different wheelbase and weight values have been designed for the analysis. Empty weight of the vehicle with a longer wheelbase is $13,500 \mathrm{~kg}$, gross vehicle weight - 19,000 kg (based on the manufacturer's data). Weight ratio on the axles is $7,500 \mathrm{~kg}$ (for front axle) and $11,500 \mathrm{~kg}$ (for rear axle) $(\sim 60.5 \%$ of total weight at the front, $39.5 \%$ - at the rear). Both models under analysis are double-axle versions. Double wishbone stabilizer suspension is applied to the front. The driving axle is a dependent suspension with dual wheels. Position of the centre of mass must be identified individually, as the references fail to provide the value. The bus is comprised of a certain number of material bodies. Mass values of these material bodies and their centres of mass are required in order to analyse movement of the bus. These parameters have been identified using a bus model divided into 19 separate elements and taking into account passengers' weight (one passenger's weight $-75 \mathrm{~kg}$ ). After the values of mass and coordinates of centres of mass have been identified for the elements, it is then possible to determine the parameters of centres of mass of the bus models.

Parameters of centres of mass of the bus models

\begin{tabular}{|l|c|c|c|c|}
\hline \multirow{2}{*}{ Bus } & \multicolumn{2}{|c|}{ Coordinates of the centre of mass $(\mathrm{mm})$} & \multicolumn{2}{c|}{ Mass distribution (\%) } \\
\cline { 2 - 5 } & $x$ & $y$ & Front & Rear \\
\hline $12 \mathrm{~m}$ empty & 6763.53 & 1437.89 & 36.40 & 63.60 \\
\hline $12 \mathrm{~m}$ gross & 6679.13 & 1584.04 & 37.78 & 62.22 \\
\hline $13 \mathrm{~m}$ empty & 7151.90 & 1446.48 & 38.32 & 61.68 \\
\hline $13 \mathrm{~m}$ gross & 7183.16 & 1612.24 & 37.87 & 62.13 \\
\hline
\end{tabular}

This is a simplified stability control model, as there is no input on the steering wheel angle. Relevance of the stability control is determined by the system on the basis of two vehicle body parameters: body lateral acceleration (body_lat_acc) and body yaw rate (body_yaw_rate).

\section{Test conditions}

The model is tested on a virtual road under different grip conditions for more comprehensive analysis of effect of the dynamic stability control system on bus stabil- 
ity. It has been decided to test the bus on the roads with, respectively, 0.8 and 0.2 grip ratio $(\mu)$ values. These values represent, respectively, dry asphalt concrete and road covered with packed snow.

Double-lane change and ramp tests (steering wheel angle slightly increased) have been performed.
Double-lane change test. The manoeuvre has been performed under the methodology developed by the Altoona Bus Research and Testing Center. The bus moves at $48 \mathrm{~km} / \mathrm{h}$ before performing the manoeuvre. Bus track before the manoeuvre is presented in Fig. 5.



$\mathrm{a}$

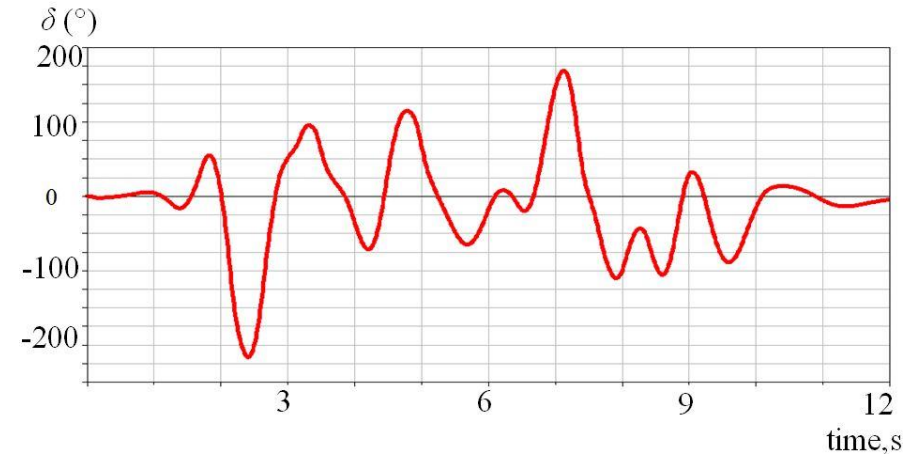

b

Fig. 5 Trajectory of double-lane change manoeuvre (a) and steering wheel angle (b) variation

Ramp test. This test is also referred to as the Slowly Increasing Steer Manoeuvre (SIS) test. The test is conducted with the steering wheel turned constantly at 13.5 degrees/second until 400 degrees of steering wheel angle is achieved. Initial bus velocity $-48 \mathrm{~km} / \mathrm{h}$ Relevant values of parameters of bus transverse stability and variables that help maintain the desired trajectory of bus.

\section{Discussion of the results}

Brake develops a certain braking torque that is de-
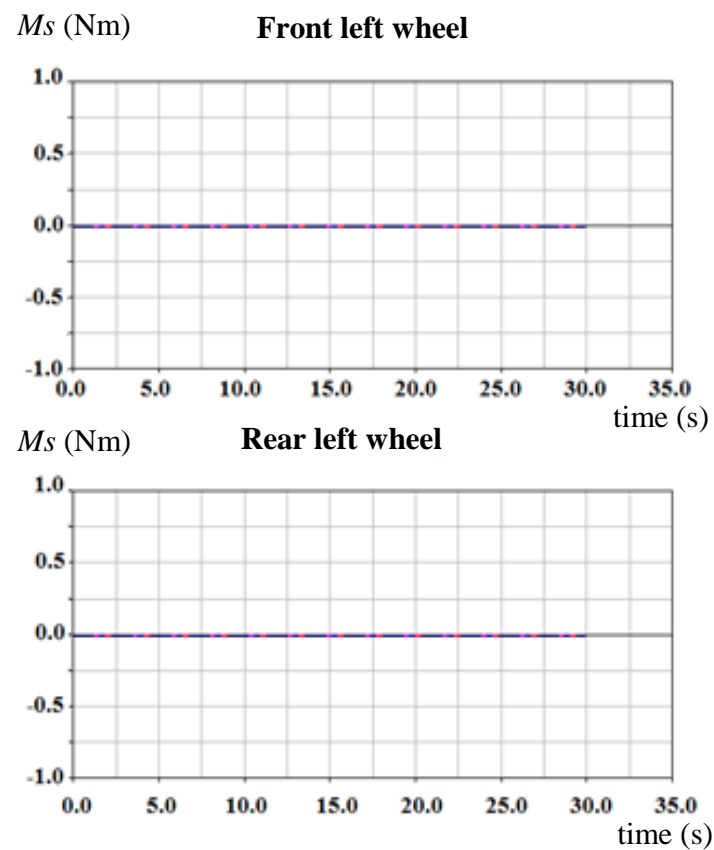

termined by the braking force and the arm of force. Arm of braking force is the radius between the force application point to the centre of brake disk. Bus model has been designed so as to ensure that its rear brakes develop lower maximum braking torque.

The ramp test manoeuvre is performed by turning the steering wheel counter-clockwise. In all cases, outer wheels are subjected to braking. Left side wheels were not subjected to braking during this manoeuvre. Front wheel is subjected to stronger breaking, thus developing a greater restoring torque.
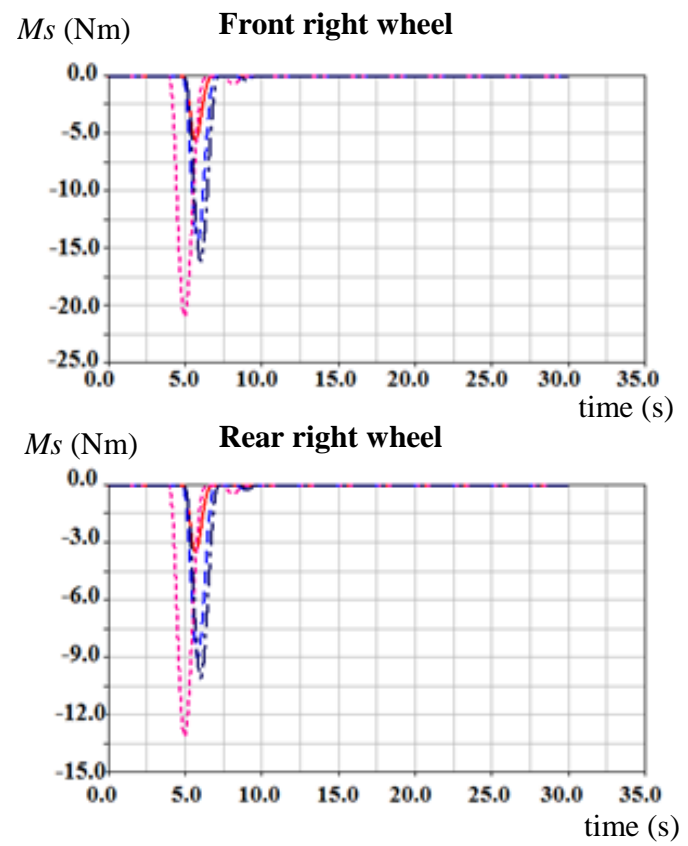



Fig. 6 Braking torques during ramp test at grip ratio $\mu=0.2$

The curves suggest that greater braking torque is required to control a fully loaded bus. It is essential to note that braking torque is considerably lower in case of slip- pery road surface (i.e. where $\mu=0.2$ ) than in other cases analysed. 

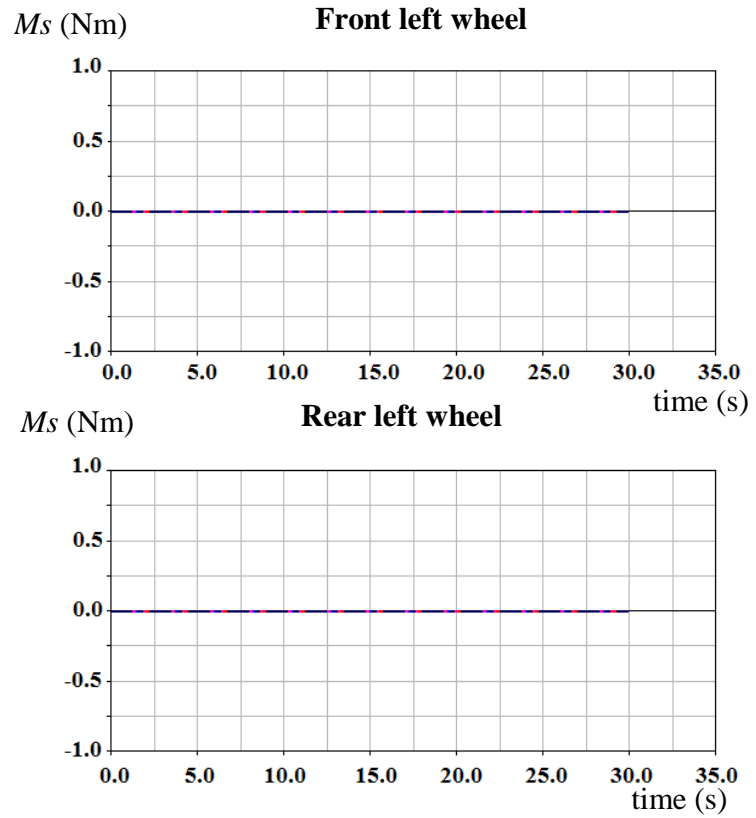
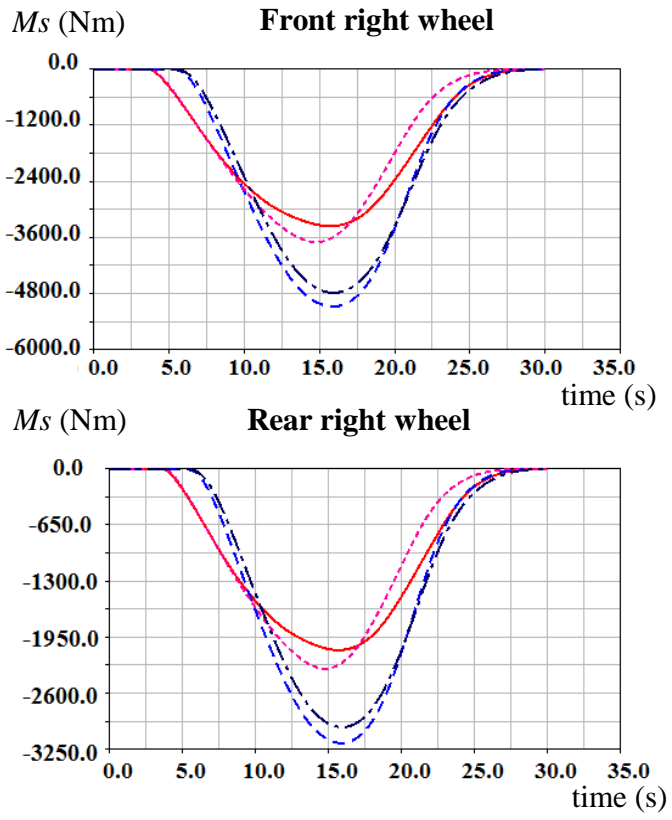

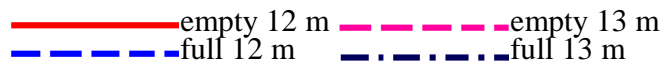

Fig. 7 Braking torques during ramp test at grip ratio $\mu=0.8$

This braking torque had just a slight effect on stabilization of the bus trajectory. This has been caused by system drawbacks, namely, failure to register considerable variation in lateral acceleration or yaws rate during slipping of front wheels. The system misinterpreted the position of the bus during its slipping in the forward direction with its wheels turned to the side, sending a wrong signal on low braking torque required to the braking actuator. In the case of slippery surface, right wheels of $13 \mathrm{~m}$ empty bus were braking at the maximum braking torque (front -
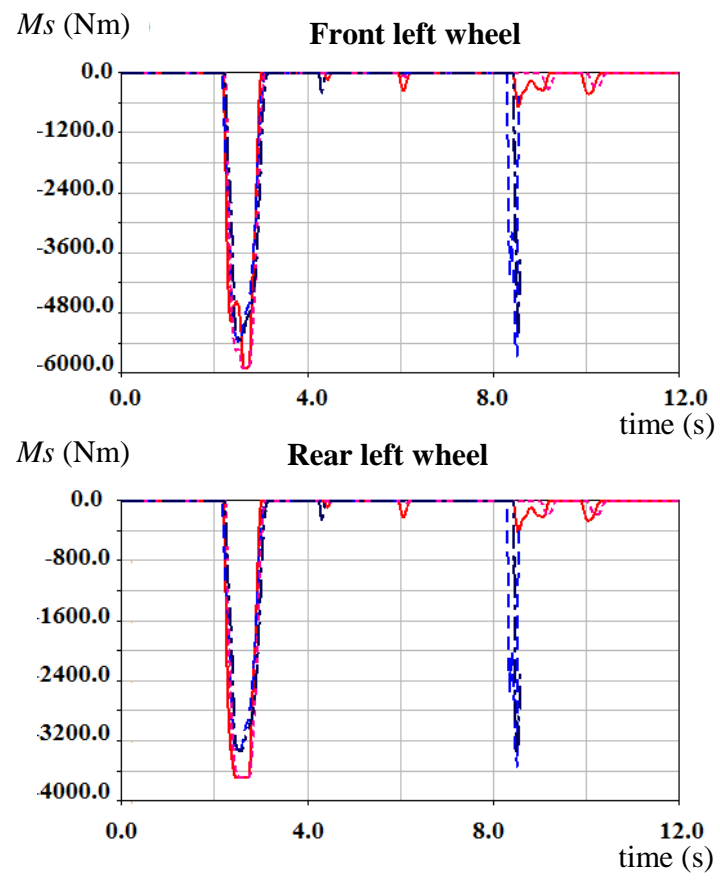

$21 \mathrm{Nm}$, rear $-13 \mathrm{Nm}$ ). It should be noted that braking of wheels of this bus model starts earlier as compared to other models analysed. Wheels of $12 \mathrm{~m}$ empty model were subjected to the weakest braking: front $-5.5 \mathrm{Nm}$, rear $3.5 \mathrm{Nm}$. Such insignificant values of braking torque do not have any greater effect on a bus weighing over 13 tons. Braking torque values generated by model test on dry asphalt are almost identical to the values generated during the manoeuvre performed on wet road surface.
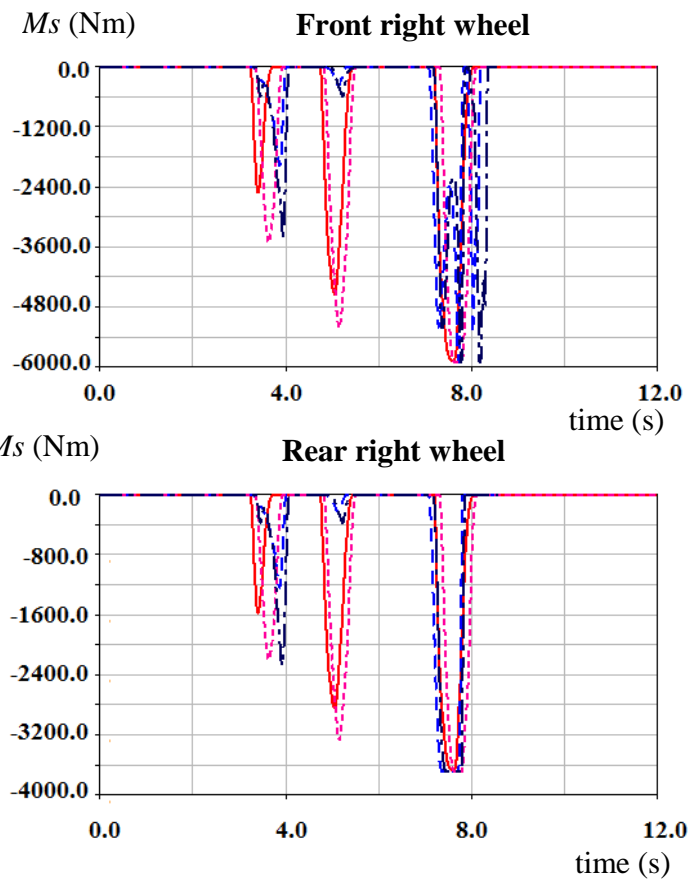

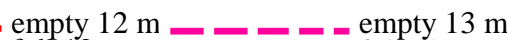



Fig. 8 Braking torques during ramp double-lane change test at grip ratio $\mu=0.8$ 

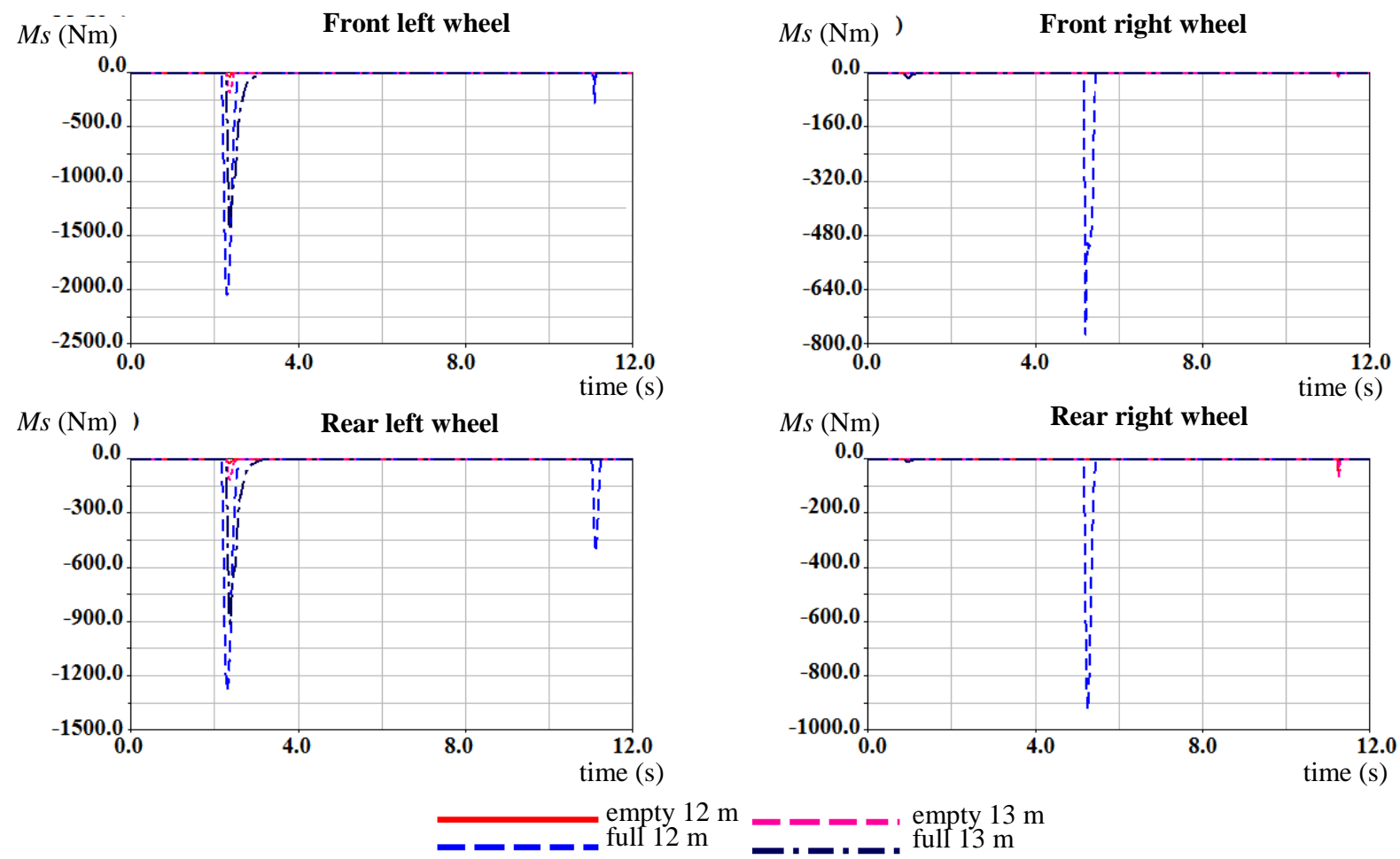

Fig. 9 Braking torques during ramp double-lane change test at grip ratio $\mu=0.2$

Maximum braking torque has been applied to control the fully loaded $12 \mathrm{~m}$ (rear right wheel $-3160 \mathrm{Nm}$, front right wheel $-5060 \mathrm{Nm}$ ). Considerably lower braking torque is required to control an empty bus of the same class, respectively, front right wheel - $3340 \mathrm{Nm}$, rear wheel $-2090 \mathrm{Nm}$. Brake activation time is similar for all cases, except for $12 \mathrm{~m}$ empty bus model. Double-lane change manoeuvre has involved initial braking of left side wheels. This is caused by the first steering wheel movement to the right. Front wheels are known to be subjected to stronger braking in order to achieve greater stabilizing torque. It should be noted that the system has applied the maximum braking torque (front - $5880 \mathrm{Nm}$, rear $3680 \mathrm{Nm}$ ) to stabilize the movement trajectory of empty bus models. Slightly lower braking force has been used to successfully stabilize the fully loaded bus models. Further into this manoeuvre, right side wheels have been subjected to braking by the system in order to straighten out the bus that has changed the lane.

Large torque has been registered while the analysed model has been changing to its initial lane. In this case, however, maximum possible torque has been applied to all tested bus models for stabilization purposes. Brake activation time is the only difference in this case. Brakes of the fully loaded $12 \mathrm{~m}$ bus have been activated within the shortest time, while brakes of the empty $13 \mathrm{~m}$ bus have been activated within the longest time. Brakes of the empty $12 \mathrm{~m}$ bus and fully loaded $13 \mathrm{~m}$ bus have been activated at the same time, with the difference in braking duration, which is longer for the fully loaded $13 \mathrm{~m}$ bus.

Double lane change manoeuvre by the empty and fully loaded buses on icy road has demonstrated that considerably greater braking torque is required in order to stabilize the fully loaded model. The greatest braking torque has been applied to the fully loaded $12 \mathrm{~m}$ bus on icy road. Wheels of this bus model have been subjected to braking at the beginning of manoeuvre (front - $2045 \mathrm{Nm}$, rear $-1280 \mathrm{Nm}$ ). Left side wheels of this model have also been observed to be subjected to braking at a fairly large braking torque (front $-772 \mathrm{Nm}$, rear $-923 \mathrm{Nm}$ ), while the wheels of other models are not subjected to any braking at the same moment of time $(t=5 \mathrm{~s})$.

NHTSA identifies two key criteria for performance assessment of a stability control system: lateral acceleration ratio (LAR) and yaw rate ratio (YRR). LAR metrics provide useful information on the system performance in roll stability control (RSC). LAR is the lateral acceleration ratio registered by the electronic system at path correction after steering to maximum lateral acceleration during steering [6].

Electronic stability control systems are usually expected to fall within the following limitations:

1. $0.75 \mathrm{~s}$ after completion of steer (stering wheel back to $0^{\circ}$ position), preceded by $0.5 \mathrm{~Hz}$ steering, at $72 \mathrm{~km} / \mathrm{h}$ vehicle speed, LAR value should be equal to or lower than $30 \%$.

$$
\frac{a_{\left(t_{0}+0.75\right)}}{a_{\max }} \times 100 \leq 30 \% ；
$$

2. $1.75 \mathrm{~s}$ after completion of steer (stering wheel back to $0^{\circ}$ position), preceded by $0.5 \mathrm{~Hz}$ steering, at $72 \mathrm{~km} / \mathrm{h}$ vehicle speed, LAR value should be equal to or lower than $10 \%$.

$$
\frac{a_{\left(t_{0}+0.75\right)}}{a_{\max }} \times 100 \leq 10 \%,
$$

where $a_{t}$ is lateral speed at time $t ; a_{\max }$ is maximum acceleration value registered at the second steer; $t_{0}$ is time moment of completion of the steer.

This factor is usually asserted to be more accurate 
assessment method than mere assessment of the effect of lateral acceleration on the vehicle analysed [6]. As a result, the following values have been registered for the models analysed:

Table 2

LAR criterion values determined

\begin{tabular}{|c|c|c|c|c|c|c|}
\hline Bus model & $\mathrm{m}$ & $\begin{array}{c}a_{\left(t_{0}+0.75\right)} \\
\left(\mathrm{m} / \mathrm{s}^{2}\right)\end{array}$ & $\begin{array}{c}a_{\left(t_{0}+1.75\right)} \\
\left(\mathrm{m} / \mathrm{s}^{2}\right)\end{array}$ & $\begin{array}{c}a_{\max } \\
\left(\mathrm{m} / \mathrm{s}^{2}\right)\end{array}$ & $\begin{array}{c}L A R_{\left(t_{0}+0.75\right)} \\
(\%) \\
\end{array}$ & $\begin{array}{c}L A R_{\left(t_{0}+1.75\right)} \\
(\%)\end{array}$ \\
\hline 12 m empty & 0.2 & 0.776 & 0.069 & 1.456 & 53.3 & 4.7 \\
\hline 12 m empty & 0.5 & 0.23 & 0.185 & 2.288 & 10.1 & 8.1 \\
\hline 12 m empty & 0.8 & 0.035 & 0.298 & 2.57 & 1.4 & 11.6 \\
\hline $12 \mathrm{~m}$ full & 0.2 & 0.998 & 0.83 & 2.534 & 39.4 & 32.8 \\
\hline $12 \mathrm{~m}$ full & 0.5 & 0.145 & 0.163 & 3.463 & 4.2 & 4.7 \\
\hline $12 \mathrm{~m}$ full & 0.8 & 0.111 & 0.064 & 3.258 & 3.4 & 2.0 \\
\hline 13 m empty & 0.2 & 1.35 & 1.36 & 2.287 & 59.0 & 59.5 \\
\hline 13 m empty & 0.5 & 0.032 & 0.173 & 2.36 & 1.4 & 7.3 \\
\hline 13 m empty & 0.8 & 0.251 & 0.205 & 2.51 & 10.0 & 8.2 \\
\hline $13 \mathrm{~m}$ full & 0.2 & 0.507 & 0.084 & 2.696 & 18.8 & 3.1 \\
\hline $13 \mathrm{~m}$ full & 0.5 & 0.111 & 0.121 & 3.438 & 3.2 & 3.5 \\
\hline $13 \mathrm{~m}$ full & 0.8 & 0.257 & 0.047 & 3.631 & 7.1 & 1.3 \\
\hline
\end{tabular}

As demonstrated by the test on $12 \mathrm{~m}$ empty and full bus of the same class on the icy road surface, the permissible values have been exceeded. LAR value has also been exceeded in $13 \mathrm{~m}$ empty bus movement simulation for the icy road surface. LAR value calculated $1.75 \mathrm{~s}$ after steering for $12 \mathrm{~m}$ empty bus on the dry road surface has been slightly exceeded.

Another important criterion to be calculated is the yaw rate ratio (YRR). YRR allows for determination of accident prevention capacity of the stability control system with respect to loss of steering control. YRR value is determined by finding the ratio of yaw rate value at a certain moment of time after steering to its peak value registered during return of the steering wheel to the straight-ahead position [6].

Two values of the ratio are calculated:

1. $0.75 \mathrm{~s}$ after completion of steer (stering wheel back to $0^{\circ}$ position), preceded by $0.5 \mathrm{~Hz}$ steering, at $72 \mathrm{~km} / \mathrm{h}$ vehicle speed, YRR value should be equal to or lower than $40 \%$.

$$
\frac{\dot{\psi}_{\left(t_{0}+0.75\right)}}{\dot{\psi}_{p i k}} \times 100 \leq 40 \% \text {; }
$$

2. $1.5 \mathrm{~s}$ after completion of steer (stering wheel back to $0^{\circ}$ position), preceded by $0.5 \mathrm{~Hz}$ steering, at $72 \mathrm{~km} / \mathrm{h}$ vehicle speed, YRR value should be equal to or lower than $15 \%$.

$$
\frac{\dot{\psi}_{\left(t_{0}+1.5\right)}}{\dot{\psi}_{p i k}} \times 100 \leq 15 \%,
$$

where $\dot{\psi}_{t}$ is yaw rate at time $t ; \dot{\psi}_{p i k}$ is peak yaw rate value in the second semi-period, generated at $0.5 \mathrm{~Hz}$ frequency steering.

NHTSA asserts that, where a stability control system satisfies the both specifications, probability of the vehicle accident related to loss of steering control is lower than $5 \%$. In addition, this criterion also provides information about how quickly the vehicle stops rotating about its vertical axis after the steering wheel is returned into its straight-ahead position [6]. The following values have been generated after completion of steering:

Table 3

YRR criterion values determined

\begin{tabular}{|c|c|c|c|c|c|c|}
\hline Bus model & $\mu$ & $\begin{array}{c}\dot{\psi}_{\left(t_{0}+0.75\right)} \\
\left(\mathrm{m} / \mathrm{s}^{2}\right)\end{array}$ & $\begin{array}{c}\dot{\psi}_{\left(t_{0}+1.5\right)} \\
\left(\mathrm{m} / \mathrm{s}^{2}\right)\end{array}$ & $\begin{array}{c}\dot{\psi}_{p i k} \\
\left(\mathrm{~m} / \mathrm{s}^{2}\right)\end{array}$ & $\begin{array}{c}Y R R_{\left(t_{0}+0.75\right)} \\
(\%)\end{array}$ & $\begin{array}{c}Y_{\left(2 R_{\left(t_{0}+1.5\right)}\right.} \\
(\%)\end{array}$ \\
\hline $12 \mathrm{~m}$ empty & 0.2 & 0.715 & 0.465 & 7.57 & 9.5 & 6.1 \\
\hline $12 \mathrm{~m}$ empty & 0.5 & 0.092 & 0.758 & 8.08 & 1.1 & 9.38 \\
\hline $12 \mathrm{~m}$ empty & 0.8 & 0.46 & 1.15 & 8.84 & 5.2 & 13.0 \\
\hline $12 \mathrm{~m}$ full & 0.2 & 0.819 & 2.27 & 10.16 & 8.1 & $\mathbf{2 2 . 3}$ \\
\hline $12 \mathrm{~m}$ full & 0.5 & 2.435 & 0.043 & 9.4 & 25.9 & 0.5 \\
\hline $12 \mathrm{~m}$ full & 0.8 & 1.49 & 0.258 & 9.55 & 15.6 & 2.7 \\
\hline $13 \mathrm{~m}$ empty & 0.2 & 4.62 & 3.67 & 9.09 & $\mathbf{5 0 . 8}$ & $\mathbf{4 0 . 4}$ \\
\hline $13 \mathrm{~m}$ empty & 0.5 & 0.13 & 0.67 & 8.81 & 1.5 & 7.6 \\
\hline $13 \mathrm{~m}$ empty & 0.8 & 0.022 & 0.67 & 8.72 & 0.3 & 7.7 \\
\hline $13 \mathrm{~m}$ full & 0.2 & 1.93 & 1.5 & 9.77 & 19.8 & $\mathbf{1 5 . 4}$ \\
\hline $13 \mathrm{~m}$ full & 0.5 & 1.61 & 0.009 & 9.683 & 16.6 & 0.1 \\
\hline $13 \mathrm{~m}$ full & 0.8 & 1.02 & 0.261 & 9.0 & 11.3 & 2.9 \\
\hline
\end{tabular}


It could be observed that the tested $12 \mathrm{~m}$ and $13 \mathrm{~m}$ empty bus models equipped with the stability control system fail to satisfy the conditions of criteria analysed when tested on the icy road surface. The value of this criterion has also been exceeded slightly during the test on $13 \mathrm{~m}$ full bus on the same icy road surface.

\section{Conclusions}

Two different bus models equipped with dynamic stability control systems have been developed during the test. System reliability has been assessed during two different manoeuvres at various tyres to road grip ratios. The calculated static parameters of transverse stability of bus models have suggested obvious lack of stability control in cases of low grip, as the system has not provided the desired trajectory. Bus models lacked manoeuvrability under such conditions, and just slid in the forward direction with the wheels turned to the side. As a result, neither the variation in lateral acceleration, nor the variation in yaw rate has been registered. Bus models have avoided rollover during the ramp manoeuvre on dry road surface with the dynamic stability control system activated. $13 \mathrm{~m}$ bus model could be considered to be the least resistant to rollover.

No rollover for bus models during double-lane change manoeuvre has been registered as the yaw angle of none of the models exceeded the critical level. The test has involved vehicle body yaw angle reduction by $22 \%$ for the bus model characterised by the highest risk (13 $\mathrm{m}$ fully loaded), on the dry road surface. The yaw rate for the same model has been reduced by $15 \%$ by application of the dynamic stability control system. The system has demonstrated maximum performance in reduction $(26 \%)$ of the maximum yaw rate for $13 \mathrm{~m}$ class empty bus manoeuvring on the wet road surface.

Rollover of the bus models has also been avoided during the ramp manoeuvre and in the case of dry road surface, with the dynamic stability control system activated. Maximum body yaw angle $4.9^{\circ}$ after application of the system has been registed for $12 \mathrm{~m}$ full bus. The same body yaw angle value has been secured during testing of the same bus on the wet road surface. The yaw angle of empty models has not exceeded $2.9^{\circ}$. The yaw rate has been reduced considerable during ramp manoeuvre while testing the empty bus models. This yaw rate value was reduced by 2.5 during testing of the $13 \mathrm{~m}$ empty bus. The system has demonstrated great performance in ensuring lateral stability of the bus.

Apparent lack of stability control has been noticed for low friction cases, where the system has failed to provide the path desired. The bus models lacked manoeuvrability under these conditions and simply were subjected to skidding forward with their wheels turned resulting in no registered change of either lateral acceleration or yaw rate ratio. Absence of reliability of the system on this type of road surface has also been supported by the LAR and YRR criteria values generated. The LAR criterion has not been fulfilled on the icy road surface: $12 \mathrm{~m}$ empty (exceeded by $23 \%$ ), $12 \mathrm{~m}$ full (exceeded by 9.4\%), and $13 \mathrm{~m}$ empty (exceeded by 29\%). 12 full model has failed to satisfy the YRR criterion conditions on the icy road surface (exceeded by $7.3 \%$ ), $13 \mathrm{~m}$ empty (10.8 and $25.4 \%$ ), while full $13 \mathrm{~m}$ class bus model has exceeded the criterion by a minor degree $(0.4 \%)$.

\section{References}

1. Volvo trucks. 2013. European Accident research and safety report. Available from Internet: http://www. volvotrucks.com/trucks/global/en-gb/newsmedia/press releases/Pages /pressreleases.aspx ?pubId=14740.

2. European Commision. 2015. Road safety knowledge base. Available from Internet: http://ec.europa.eu/ transport/road_safety/specialist/knowledge/vehicle/safe ty_design_needs/buses_and_coaches_en.htm.

3. Department of Infrastructure, Regional Development and Local Goverment. 2008. Regulation Impact Statement for the Control of Vehicle Stability. Australia. Available from Internet: http://www.puntofocal.gov.ar/ notific_otros_miembros/aus63_t.pdf.

4. WABCO. 2004. Electronic Stability Control for Commercial Vehicles. 8 p. Available from Internet: http:// www.wabcoauto.com/fileadmin/New\%20Structure $\% 20$ 2012/Products $\% 202012 / 06 \% 20$ Stability $\% 20$ Control/1 \%20ESC/ESC_rochure_2004_en_8200013063.pdf

5. Pearson, B.; Gardner, B. 2011. Benefits of Heavy Vehicle Stability Safety Technologies, Pearsons Transport Resource Centre, 35 p. Available from Internet: https://www.tmr.qld.gov.au/-/media/busind/Heavyvehi cles/stabsafetytech/Report_Benefits_of_heavy_vehicle _stability_safety_technologies.pdf?la=en

6. NHTSA. 2012. FMVSS No. 136 Electronic Stability Control Systems On Heavy Vehicles. Available from Internet: http://www.nhtsa.gov/Laws+\&+Regulations/ Electronic+Stability+Control+\%28ES

7. NHTSA. 2013. Test Track Lateral Stability Performance of Motorcoaches Equipped With Electronic Stability Control Systems. DOTHS 811633

8. LTI. 2006. Bus Test Report PTI-BT-R0512. The Pennsylvania Transportation Institute. Bus Testing and Research Center. Available from Internet: http://www.dot. state.pa.us/public/Bureaus/PublicTransportation/procur ement/Bus\%20Test\%20Reports/BusTestReportPTI-BT R0512-PCID1133LOWFLOOR.pdf

9. Reński, A. 2000. Modelowanie kierowcy w układzie kierowca-pojazd-otoczenie, Oficyna Wydawnicza Politechniki Warszawskiej, Warszawa. (in Polish)

10. Sar, H.; Reński, A.; Pokorski, J. Investigation of the tyre characteristics under non-steady-state conditions on the basis of road tests, Proceedings of the Institution of Mechanical Engineers, Part D: Journal of Automobile Engineering 231(1): 3-15. https://doi.org/10.1177/0954407016629517.

11. Gäfvert, M.; Lindgärde, O. 2004. A 9-DOF tractor semitrailer dynamic handling model for advanced chassis control studies, Vehicle System Dynamics 41(1): 51-82. https://doi.org/10.1076/vesd.41.1.51.23408.

12. Lozia, Z. 1998. Analiza Ruchu Samochodu Dwuosiowego Na Tle Modelowania Jego Dynamiki, Oficyna Wydawnicza Politechniki Warszawskiej (in Polish), $173 \mathrm{p}$.

13. Pacejka, H.B. 1987. Lateral dynamics of road vehicles, Vehicle System Dynamics 16: 75-120. https://doi.org/10.1080/00423118708969172

14. Pacejka, H.B. Spin: camber and turning, Vehicle System Dynamics 43: 3-17. https://doi.org/10.1080/00423110500140013.

15. Rajamani, R. 2006. Vehicle Dynamics and Control, 
Springer, 485p.

16. Vlček, M. 2011. Optimization of car yaw behaviour using active suspension elements. SVOČ - FST 2011. 10p. Available from Internet: http://old.fst.zcu.czl_files _web_FST/_SP_FST\%28SVOC\%29/_2011/_sbornik/P apersPdf/PhD/Vlcek_Martin.pdf

17. Help of MSC Software. Adams/Mechatronics. 2013.
V. Dzerkelis, V. Lukoševičius, E. Girkontas, R. Keršys, H. Sar, R. Makaras, R. Skvireckas

\section{MODELING AND RESEARCH OF BUS EQUIPPED WITH DYNAMIC STABILITY CONTROL SYSTEM}

S u m mary

This paper is aimed at analysing manoeuvre stability of an intercity bus equipped with dynamic stability control system using the MSC Adams software. The study has been performed using the dynamic stability control system functioning under the principle and structure of distributed braking. Bus models have been developed on the basis of analysis results of in situ test methodology applied to analysis of heavy-duty vehicles. Numerical model has been designed as part of this study for assessment of reliability and relevance of the system in buses of similar type. Model parameters affecting the bus dynamics while cornering have been identified and graph of braking torques acting in the vehicle wheels have been developed during analysis of the results.

Keywords: bus, lateral stability, dynamic stability control, ESP, MSC.Adams.

Received May 26, 2017

Accepted February 15, 2018 